\title{
PREDICTION OF COGNITIVE LEARNING PERFORMANCE FROM MULTIVARIATE STATE-CHANGE SCORES
}

\author{
Gregory J. Boyle \\ University of Melbourne
}

ACKNOWLEDGEMENT: The author is indebted to Professor Brian Start, and to Professor Gordon Stanley, University of Melbourne for their encouragement and support in conducting this research.

\begin{abstract}
While the role of non-ability intrapersonal variables including personality traits and motivational dynamic factors has been well documented in numerous studies, the relationship of transient states to cognitive performance has been relatively neglected. Boyle (1983b, 1986) demonstrated that emotional states powerfully influence cognitive learning outcomes under conditions of stressful activation. However, under neutral, non-emotive conditions, it remained unclear what role if any was played by mood states in cognitive learning. The failure to employ change measures in these studies may have obscured the likely influence of emotions on cognitive performance in the neutral situation. This study re-examines the relationship of moods with cognitive learning performance using state-change scores rather than single-occasion mood-state scores as the basis for predicting cognitive learning outcomes.
\end{abstract}

\section{INTRODUCTION}

Cognitive learning performance is not only a function of intellectual ability, but also of various other intrapersonal factors, including personality trait, motivational dynamic factors, and emotional states. The early literature in this area was summarised in an integration by Cattell and Butcher (1968). Since the publication of this seminal work, there has been a plethora of further studies in this area, as evidenced by the numerous articles which have appeared in the scientific literature. In particular, a further integration was provided by Cattell and Child (1975). The major finding of several of these studies has been that the various intrapersonal psychological factors can account for as much as $60-75$ per cent of the variance involved in cognitive learning (cf. Gillis \& Lee, 1978, p. 241 , in regard to the prediction of performance in mathematics and reading). The work of Cattell, Barton and Dielman (1972), and Dielman, Barton and Cattell $(1971,1973)$ was particularly germane in this regard (cf. Cattell, 1983b, pp. 255-258, 1985, p. 112).

In a recent study of this area, Boyle (1983b) investigated the effects of emotionally disturbing stimuli on cognitive learning performance. Using a fiveminute documentary film-segment which displayed graphic scenes of motor car accident victims as well as part of a post-mortem of a road crash victim, and despite the consequent interference with cognitive information processing, there was a very highly significant increase in predictive variance due to enhanced correlations between the cognitive learning performance and the non-ability intrapersonal variables. Prior to this study by Boyle (1983b), relatively little was known about the influence of transitory emotional states on cognitive learning (cf. Boyle, 1979). A notable finding was that of the eight states measured in the Eight State Questionnaire (8SQCurran \& Cattell, 1976), no less than seven of these exhibited significant correlations with cognitive learning performance under the highly stressful aversive learning condition. However, for a neutral control group not exposed to any particular emotional activation, none of the states correlated significantly with cognitive performance, even though the 8SQ had been given immediately prior to the time of learning itself, in the belief that emotional states at about the time of learning would significantly influence performance. Previously, Kline (1979) had argued that the influence of intrapersonal psychological variables on cognitive learning performance is slight, with most of the correlations being small and insignificant. However, Boyle's (1983b) study demonstrated unequivocally the powerful effect of mood states on cognitive information processing (cf. Boyle, 1983a).

In a subsequent investigation of the role of transitory emotional states on cognitive learning performance, Boyle (1986) examined the influence of mild depressed mood (induced via the Velten, 1968, mood-induction procedure) on both encoding and retrieval of cognitive material. It was found that depressed mood at encoding (involving several of the emotional states measured in Izard's Differential Emotions Scale-cf. Boyle 1984) adversely affected cognitive processing, whereas at retrieval no significant debilitating effect on cognitive performance was noticed. Taken together, the studies by Boyle (1983b, 1986) demonstrated that emotional states play a very significant role in influencing cognitive learning outcomes, under conditions of emotional activation. However it remained unclear what role, if any, emotional states play under conditions of neutral mood. The present study explored further this question by examining the relationship of the various $8 S Q$ change scores to the prediction of cognitive perfomance for the nontreatment (neutral) group in Boyle's (1983b) study.

\section{METHOD}

\section{Subjects and Procedure}

The subjects used in the present investigation were 66 student teachers (mostly females) whose mean age was 24.52 years (S.D. - 7.04 years). The demographic characteristics of this sample were described in Boyle 
(1983b). The 8SQ (which is purported to measure Anxiety, Stress, Depression, Regression, Fatigue, Guilt, Extraversion, and Arousal) was administered to the sample of student teachers on two separate occasions three weeks apart. Five minutes later, the two cognitive learning tasks were presented in counterbalanced fashion (one task involved reading a complex textual passage, while the other required the students to listen to a tape-recorded lecture of approximately the same length as the prose material). Posttests of immediate factual retention for each cognitive learning task quantified the short-term learning performance of the students on the cognitive tasks (using an objective multiple-choice format with counterbalanced questions).

\section{RESULTS AND DISCUSSION}

The 8SQ state scores differed significantly across the two measurement occasions as evidenced by the stability coefficients which were obtained for each of the eight subscales in the instrument. Table 1 presents these data along with the corresponding dependability estimates for the single-occasion scores and separately for the change scores. For a reliable state instrument, high dependability (using single-score date) coefficients together with lower stability coefficients would be predicted, if the instrument is situationally sensitive to different levels of emotional activation (cf. Boyle, 1985). Table 1 clearly demonstrates that the $8 \mathrm{SQ}$ subscale scores were reliable, and more particularly, that the $8 \mathrm{SQ}$ change scores were quite reliable in the present investigation.
A detailed discussion of the reliability of change scores is provided in Cattell (1982) where it was shown that if there is little correlation between scores on the two measurement occasions, the proportion of error variance to true variance is not significantly increased when working with change scores rather than singleoccasion scores. This is an important consideration, as it implies that the reliabilities calculated in Table 1 for the $8 S Q$ change scores are reasonably accurate. Moreover, when working with state measures, it is clearly important to undertake the data analyses on the change scores, as these represent the actual dimensions of state change. If analyses are restricted to single-occasion scores alone, it follows that significant trait contamination is inherent in the data.

The means and standard deviations for the 8SQ change scores are presented in Table 2.

Since each subscale in the 8SQ has 12 items, it is evident that all subscales exhibited moderate changes across occasions, in accord with the stabilities in Table 1 above. The means and standard deviations for the Sixteen Personality Factor Questionnaire (16PF) and Motivation Analysis Test (MAT) characteristics of the sample are shown in Tables 3 and 4 respectively.

Table 1

Reliability Estimates for Change Scores

8SQ Subscale

Anxiety

Stress

Depression

Regression

Fatigue

Guilt

Extraversion

Arousal

\section{Single-Score \\ Dependabilities}

.91

.95

.96

.94

.92

.96

.96

.92

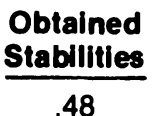

.51

.49

.48

.48

.65

.55

.53

\section{Change-Score \\ Dependabilities}

.83

.90

.92

.88

.85

.89

.91

.83

Notes:

Single-score dependabilities $\left({ }^{r} d\right)$ taken from Curran and Cattell (1976, p.14).

Stabilities ( $s$ ) based on total 135 subjects with the $8 \mathrm{SQ}$ administered on both measurement occasions under neutral emotional conditions (both the treatment and non-treatment groups took the 8SQ under neutral conditions - see Boyle, 1983b).

Change-score dependabilities ( $\left.{ }^{r} d(2-1)\right)$ were calculated via the formula:

$d(2-1)=\frac{r_{d}-r_{s}}{1-r_{s}}-$ (cf. Cattell, 1982, p.95). 
Table 2

Means and Standard Deviations for Change Scores

\section{SQ Subscale}

Anxiety

Stress

Depression

Regression

Fatigue

Guilt

Extraversion

Arousal

\section{M}

6.36

4.52

5.24

4.24

6.06

4.64

$-4.46$

$-4.94$
S.D.

5.05

2.94

4.52

3.92

5.71

4.33

4.08

3.66

Note:

Use of state-change scores avoids the problem of trait contamination which is inherent in singleoccasion mood-state scores.

Table 3

Personality Trait Characteristics

of the Present Sample

\section{PF Subscale}

$\begin{array}{ll}\text { A } & \text { Warmth } \\ \text { B } & \text { Intelligence } \\ \text { C } & \text { Emotional Stability } \\ \text { E } & \text { Dominance } \\ \text { F } & \text { Impulsivity } \\ \text { G } & \text { Conformity } \\ \text { H } & \text { Boldness } \\ \text { I } & \text { Sensitivity } \\ \text { L } & \text { Suspiciousness } \\ \text { M } & \text { Imagination } \\ \text { N } & \text { Shrewdness } \\ \text { O } & \text { Insecurity } \\ \text { Q1 } & \text { Radicalism } \\ \text { Q2 } & \text { Self-Sufficiency } \\ \text { Q3 } & \text { Self-Sentiment } \\ \text { Q4 } & \text { Tension }\end{array}$

\section{M}

10.80

8.64

14.82

10.89

15.46

11.20

12.38

14.03

8.49

12.41

9.77

11.74

7.61

10.21

11.53

14.11
S.D.

2.88

1.75

3.24

3.58

4.64

3.52

5.81

2.48

2.93

3.57

2.68

3.77

2.78

3.15

3.10

4.31

Note: Personality traits as indexed in the Sixteen Personality Factor Questionnaire, for all 66 student teachers in the present sample. 


\section{MAT Subscale}

Career-U

Career-I

Home-U

Home-I

Fear-U

Fear-1

Narcism-U

Narcism-I

Superego-U

Superego-I

Self-U

Self-I

Mating- $U$

Mating-I

Pugnacity-U

Pugnacity-I

Assertion-U

Assertion-1

Spouse-U

Spouse-I

Note:

\section{M}

9.29

6.46

12.73

6.38

8.18

4.68

8.92

6.24

20.79

12.59

37.71

18.32

11.71

4.76

7.85

4.44

9.89

3.86

8.67

7.80
S.D.

2.10

1.28

2.34

1.52

2.54

1.23

2.04

1.42

3.29

2.13

5.78

3.14

2.10

1.55

2.54

1.92

2.19

1.21

2.24

1.76

Motivational dynamic factors as indexed in the Motivation Analysis Test (Cattell et al., 1964) for all 66 student teachers in the present sample.

U-components are the unintegrated/unconscious motivation dimensions, while the I-components are the integrated/conscious dimensions for each of the 10 motivational factors measured in the MAT.

Table 5

Correlations of State-Change Scores with Cognitive Learning Performance

\section{SQ Subscale}

Anxiety

Stress

Depression

Regression

Fatigue

Guilt

Extraversion

Arousal

Notes:
Textual

Passage

$-.31^{* *}$

$-.38^{* * *}$

$-.04$

$-.28^{* *}$

$-.21^{*}$

$-.08$

.15

$.25^{*}$

\begin{tabular}{c}
$\begin{array}{c}\text { Tape-Recorded } \\
\text { Lecture }\end{array}$ \\
\hline-.02 \\
$-.23^{\star}$ \\
.05 \\
-.16 \\
$-.22^{\star}$ \\
-.04 \\
.04
\end{tabular}

$.23^{*}$
Total

Achlevement

$-.18$

$-.33^{* *}$

.01

$-.25^{*}$

$-.26^{*}$

$-.07$

.10

$.29 *$ 
Regarding the correlations of the 8SQ change scores with the posttest scores, predictive of cognitive learning performance, Table 5 presents these data. As is immediately apparent, four of the states measured in the 8SQ correlated significantly with learning performance overall (namely, Stress, Regression, Fatigue, and Arousal/Alertness). Accordingly, the finding in Boyle (1983b) that under neutral emotional conditions emotional states appeared to have little, if any, relationship with learning outcomes is shown upon closer analysis not to be absolutely valid. In fact when change scores rather than single-occasion scores are employed in the analysis, it is clear that even under neutral conditions, emotional states significantly influence learning outcomes. Previous analyses have failed to detect this relationship because of the almost exclusive reliance on single-occasion measures rather than the more appropriate change measures used in the present instance.

\section{SUMMARY AND CONCLUSIONS}

On the basis of the present findings it seems that (1) non-ability intrapersonal factors play a very significant role in the prediction of cognitive learning performance; (2) transitory emotional states significantly influence cognitive learning outcomes under both non-emotive, neutral emotional conditions and aversive/stressful emotional activation; (3) the subtle role of emotional states in learning is more clearly delineated when using change scores rather than single-occasion scores (which necessarily include significant trait contamination variance); (4) change scores are not inevitably unreliable, and in certain situations including the present study, are actually quite reliable measures of state-change dimensions; (5) the importance of multivariate measurement is demonstrated, wherein it is shown that Anxiety, Stress, Regression and Fatigue all have a negative relationship with cognitive learning performance, while Arousal/Alertness relates positively to learning outcomes.

\section{REFERENCES}

Boyle, G.J. (1979). Delimitation of state-trait curiosity in relation to state anxiety and learning task performance. Australian Journal of Education, 23, 70-82.

Boyle, G.J. (1983a). Critical review of state-trait curiosity test development. Motivation and Emotion, 7, 377-397.

Boyle, G.J. (1983b). Effects on academic learning of manipulating emotional states and motivational dynamics. British Journal of Educational Psychology, 53, 347-357.

Boyle, G.J. (1984). Reliability and validity of Izard's Differential Emotions Scale. Personality and Individual Differences, 5, 747-750.

Boyle, G.J. (1985). Self-report measures of depression: Some psychometric considerations. British Journal of Clinical Psychology, 24, 45-59.

Boyle, G.J. (1986). Depressed mood effects on processing of high- and low-content structure text in American and Australian college women. Journal of Structural Learning, 9, 77-82.
Cattell, R.B. (1982). The clinical use of difference scores: Some psychometric problems. Multivariate Experimental Clinical Research, 6, 87-98.

Cattell, R.B. (1983a). Structured personality-learning theory: A wholistic multivariate research approach. New York: Praeger.

Cattell, R.B. (1983b). The role of psychological testing in educational performance: The validity and use of ability predictions. Mankind Quarterly, 23, 227-277.

Cattell, R.B. (1985). Human motivation and the dynamic calculus. New York: Praeger.

Cattell, R.B. \& Butcher, H.J. (1986). The prediction of achievement and creativity. Indianapolis: BobbsMerrill.

Cattell, R.B. \& Child, D. (1975). Motivation and dynamic structure. New York: Wiley-Halsted.

Cattell, R.B., Barton, K. \& Dielman, T.E. (1972). Prediction of school achievement from motivation, personality and ability measures. Psychological Reports, 30, 35-43.

Curran, J.P. \& Cattell, R.B. (1976). Manual for the Eight State Questionnaire. Champaign, Illinois: Institute for Personality \& Ability Testing.

Dielman, T.E., Barton, K. \& Cattell, R.B. (1971). The prediction of junior high school achievement from objective motivation tests. Personality, 4, 279-287.

Dielman, T.E., Barton, K. \& Cattell, R.B. (1973). The prediction of junior high school grades from the Culture Fair Intelligence Test and objective measures of motivation. Champaign, Illinois: Institute for Personality \& Ability Testing.

Gillis, J.S. \& Lee, D.C. (1978). Second-order relations between different modalities of personality trait organization. Multivariate Experimental Clinical Research, 3, 241-248.

Kline, P. (1979). Psychometrics and psychology. London: Academic.

Velten, E. (1968). A laboratory task for induction of mood states. Behaviour Research and Therapy, 6, 473482. 